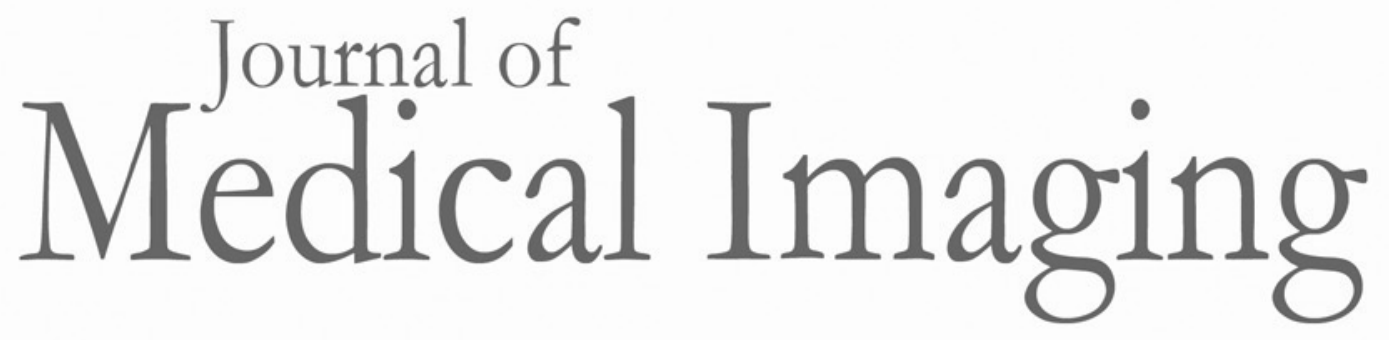

Medicallmaging.SPIEDigitalLibrary.org

\title{
Errata: Evaluation of models of spectral distortions in photon- counting detectors for computed tomography
}

Jochen Cammin

Steffen Kappler

Thomas Weidinger

Katsuyuki Taguchi 


\title{
Errata: Evaluation of models of spectral distortions in photon-counting detectors for computed tomography
}

\author{
Jochen Cammin, ${ }^{a}$ Steffen Kappler,, ${ }^{b}$ Thomas Weidinger,, ${ }^{b, c}$ and Katsuyuki Taguchi ${ }^{a}$ \\ a Johns Hopkins University School of Medicine, Division of Medical Imaging Physics, The Russell H. Morgan Department of Radiology and \\ Radiological Science, 601 North Caroline Street, Baltimore, Maryland 21287, United States \\ ${ }^{b}$ Siemens Healthcare, Computed Tomography, Siemens Street 1, Forchheim 91301, Germany \\ 'University of Lübeck, Institute of Medical Engineering, Ratzeburger Allee 160, Lübeck 23562, Germany
}

[DOI: 10.1117/1.JMI.3.2.029801]

This article [J. Med. Imag. 3(2), 023503 (2016)] was originally published online on 6 May 2016 with a copyeditor error in the abstract. The sentence "The data-model agreement expressed as weighted coefficient of variation $\left(\mathrm{COV}_{\mathrm{W}}\right)$ was better than $\mathrm{COV}_{\mathrm{W}}=20 \%$ for dead time losses..." has been changed to read: "The data-model agreement expressed as weighted coefficient of variation $\left(\mathrm{COV}_{\mathrm{W}}\right)$ was better than $\mathrm{COV}_{\mathrm{W}}=$ $2.0 \%$ for dead time losses..." The $\mathrm{COV}_{\mathrm{W}}$ value was missing a decimal point.

This article was corrected online on 11 May 2016. It appears correctly in print. 